\title{
Detailed design analysis of erbium-doped fiber amplifiers
}

Pedersen, Bo; Bjarklev, Anders Overgaard; Lumholt, Ole; Povlsen, Jørn Hedegaard

Published in:

I E E E Photonics Technology Letters

Link to article, DOI:

$10.1109 / 68.9103$

Publication date:

1991

Document Version

Publisher's PDF, also known as Version of record

Link back to DTU Orbit

Citation (APA):

Pedersen, B., Bjarklev, A. O., Lumholt, O., \& Povlsen, J. H. (1991). Detailed design analysis of erbium-doped fiber amplifiers. I E E E Photonics Technology Letters, 3(6), 548-550. https://doi.org/10.1109/68.9103

\section{General rights}

Copyright and moral rights for the publications made accessible in the public portal are retained by the authors and/or other copyright owners and it is a condition of accessing publications that users recognise and abide by the legal requirements associated with these rights.

- Users may download and print one copy of any publication from the public portal for the purpose of private study or research.

- You may not further distribute the material or use it for any profit-making activity or commercial gain

- You may freely distribute the URL identifying the publication in the public portal

If you believe that this document breaches copyright please contact us providing details, and we will remove access to the work immediately and investigate your claim 


\title{
Detailed Design Analysis of Erbium-Doped Fiber Amplifiers
}

\author{
Bo Pedersen, Anders Bjarklev, Ole Lumholt, and Jørn Hedegaard Povlsen
}

\begin{abstract}
When pumping the erbium-doped fiber amplifier at 0.98 and $1.48 \mu \mathrm{m}$, the optimum cutoff wavelength for step profiles with arbitrary numerical aperture is shown to be 0.80 and $0.90 \mu \mathrm{m}$, respectively. The use of a confined erbium profile can improve the gain coefficient up to $45 \%$. The index raising co-dopant is shown to be very significant for the gain coefficient when pumping at $0.98 \mu \mathrm{m}$.
\end{abstract}

\section{INTRODUCTION}

THE erbium-doped fiber amplifier has much potential as a high-gain optical amplifier in optical communication systems based on signal wavelength around $1.55 \mu \mathrm{m}$. The latest reports [1], [2] of high gain obtained with low pump power from sources emitting at 1.48 and $0.98 \mu \mathrm{m}$ have stimulated the interest for these two pump wavelengths.

In this letter, a comprehensive analysis of the fiber design will be performed. The analysis will concentrate on the pump wavelengths of 1.48 and $0.98 \mu \mathrm{m}$. Further, the analysis includes a comparison of the amplifier performance when using the index raising co-dopants aluminum and germanium.

\section{MODEL}

The model for the EDFA, used in the analysis, assumes that the $\mathrm{Er}^{3+}$-ions acts as a 3-level laser system when pumping at $0.98 \mu \mathrm{m}$ and as a partial 2-level laser system when pumping at $1.48 \mu \mathrm{m}$. The model is a generalized version of the 3-level laser model presented in [3]. In the generalized model, the population concentration in the upper laser level, $n_{2}$, is calculated as

$$
\begin{array}{r}
n_{2}(r, z)=\rho_{\mathrm{Er}}(r) \cdot \frac{W_{p a}(r, z)+W_{s a}(r, z)}{W_{p a}(r, z)+W_{p e}(r, z)+W_{s a}(r, z)} \\
+W_{s e}(r, z)+A_{s p}
\end{array}
$$

where $\rho_{\mathrm{Er}}$ is the erbium concentration, $W_{p a}$ and $W_{p e}$ are the pump absorption and emission rate, $W_{s a}$ and $W_{s e}$ are the signal absorption and emission rate, and $A_{s p}$ is the spontaneous emission rate. For $0.98 \mu \mathrm{m}$ pumping, $W_{p e}$ is clamped to zero, and consequently the 3-level laser model [3] is adopted (no excited state absorption at $0.98 \mu \mathrm{m}$ ). The model

Manuscript received December 27, 1990; revised March 11, 1991. This work was supported by the Danish Technical Research Council and the National Agency of Industry and Trade, Denmark.

The authors are with the Technical University of Denmark, Electromagnetics Institute, Center for Broadband Telecommunications, DK-2800 Lyngby, Denmark.

IEEE Log Number 9100345. has previously [3] been shown to accurately predict small signal gain, amplified spontaneous emission, and residual pump power.

\section{DESIGN}

When designing the index profile and the erbium concentration profile of the EDFA, the design criterion is not only to maximize the gain for a given available pump power, but also to minimize the needed pump power for a desired gain. The latter design criterion is posed because a decrease in pump power will lead to an increase in the lifetime of the pump laser diodes. With respect to these two criteria, the gain coefficient is introduced as the maximum ratio between the small signal gain (in decibels) and the launched pump power (in milliwatts). This maximum ratio is determined by changing the pump power, calculating the maximum small signal gain for the specific pump power, until the maximum ratio is obtained. The erbium-concentration does not appear in the analysis because all fiber lengths are optimized with regard to maximum small signal gain.

The resulting gain coefficient is very sensitive to the accuracy of the wavelength-dependent cross sections used by the model. Fig. 1 shows the emission, $\sigma_{21}(\lambda)$, and the absorption, $\sigma_{12}(\lambda)$, cross-section spectra as used in this analysis. These cross sections have been carefully determined from fluorescence and absorption measurements [3], [4] on three erbium-doped fibers. The first fiber has aluminum as index raising co-dopant (upper figure). The second fiber has both aluminum and germanium as co-dopants (middle figure). The third fiber is co-doped with Germanium only (lower figure). The fluorescence lifetimes for the three fibers were measured to be $10.6,11.4$, and $12.5 \mathrm{~ms}$, respectively. As seen from Fig. 1, the spectra for the Ge-Er fiber are more narrow than the spectra for the $\mathrm{Al}-\mathrm{Er}$ fiber around $1.53 \mu \mathrm{m}$. The spectra for the Al-Ge-Er fiber are combinations of the spectra from the Al-Er fiber and the spectra from the $\mathrm{Ge}-\mathrm{Er}$ fiber.

The absorption cross sections at $0.98 \mu \mathrm{m}$ were determined from the measured attenuation spectra. The resulting value for the $\mathrm{Ge}-\mathrm{Er}$ fiber is $4.5 \times 10^{-25} \mathrm{~m}^{2}$, more than twice the maximum value of $2 \times 10^{-25} \mathrm{~m}^{2}$ for the Al-Er fiber. For the $\mathrm{Al}-\mathrm{Ge}-\mathrm{Er}$ fiber, the absorption cross section at $0.98 \mu \mathrm{m}$ was determined to be $3.8 \times 10^{-25} \mathrm{~m}^{2}$.

Fig. 2 shows the gain coefficient versus the cutoff wavelength for the $\mathrm{LP}_{11}$-mode in a step-index $\mathrm{Al}$-Er fiber pumped at $0.98 \mu \mathrm{m}$ (solid curves) as well as at $1.48 \mu \mathrm{m}$. Curves are shown for a fixed numerical aperture NA $=0.1-0.4$ in steps of 0.05 . The signal wavelength is $1.530 \mu \mathrm{m}$. The erbium- 


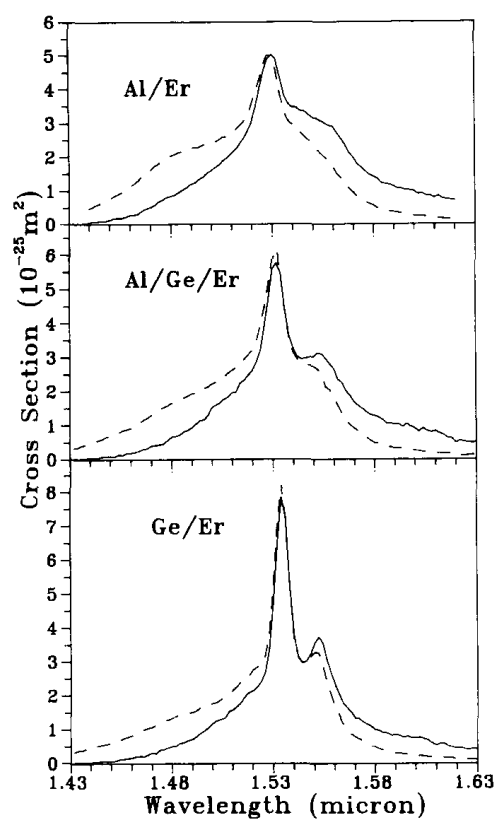

Fig. 1. Experimentally determined emission (dashed) and absorption cross section spectra for erbium-doped fiber. Upper figure: the index raising co-dopant is aluminum. Middle figure: the index raising co-dopants are aluminum and germanium. Lower figure: the index raising co-dopant is germanium.

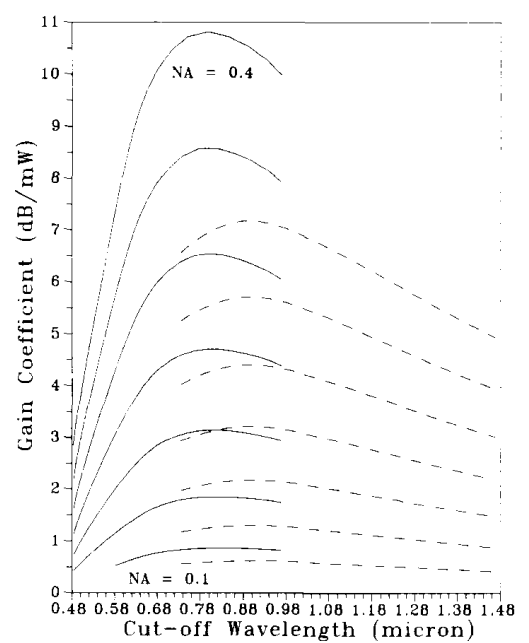

Fig. 2. Gain coefficient versus cutoff wavelength for step index $\mathrm{Al}-\mathrm{Er}$ fibers pumped at $0.98 \mu \mathrm{m}$ (solid) and at $1.48 \mu \mathrm{m}$. Curves are shown for $\mathrm{NA}=0.1-0.4$ in steps of 0.05 .

concentration profile follows the step-index profile. As seen from the figure, the optimum cutoff wavelengths $-0.8 \mu$ for $0.98 \mu$ pumping, and $0.9 \mu$ for $1.48 \mu$ pumping-are independent of the numerical aperture (NA). These cutoff wavelengths can also be shown to be valid for the Al-Ge-Er and the Ge-Er fiber. It has been shown [5] that design optimization of the gain for $1.48 \mu$ pumping corresponds to a minimization of the threshold pump power, defined as the

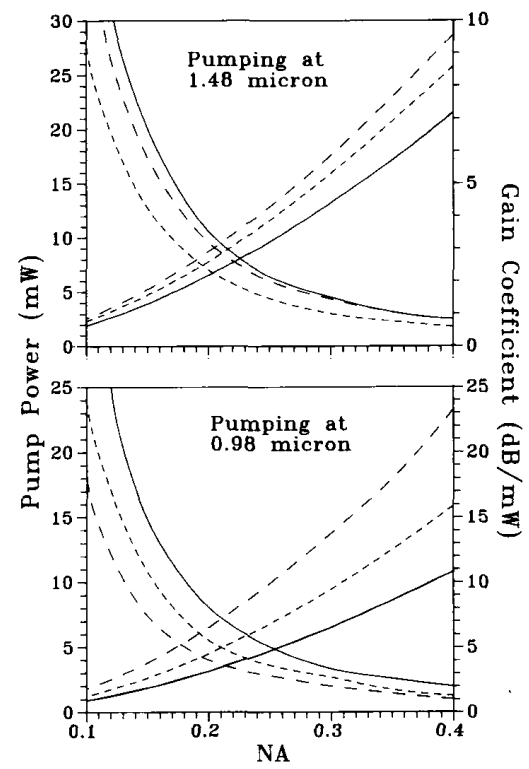

Fig. 3. Input pump power (decreasing curves) and gain coefficient versus $\mathrm{NA}$ in step index $\mathrm{Er}^{3+}$ fibers. Upper figure: pumping at $1.48 \mu \mathrm{m}$. Lower figure: pumping at $0.98 \mu \mathrm{m}$. Solid curves: the index raising co-dopant is aluminum. Small dashes: the index raising co-dopants are aluminum and germanium. Long dashes: the index raising co-dopant is germanium.

pump power needed to obtain a gain of $0 \mathrm{~dB}$ for an infinitesimal fiber length. The threshold pump power is reverse proportional to the overlap integral between the erbium profile and the pump mode. However, the overlap integral between the signal mode and the erbium profile has to be considered too. If this overlap integral is decreased, the number of erbium ions that have to be inverted to obtain the maximum gain will increase. Consequently, the spontaneous emission power will increase yielding a less efficient amplifier. The optimum cutoff wavelength, reported in this letter, is compromising the cutoff wavelength that gives the highest overlap integral between the erbium profile and, respectively, the pump and signal mode.

Fig. 3 shows the gain coefficients (increasing curves) and the pump powers needed to obtain the gain coefficients versus the NA for step-index erbium-doped fibers. Results for $\mathrm{Al}-\mathrm{Er}, \mathrm{Al}-\mathrm{Ge}-\mathrm{Er}$, and $\mathrm{Ge}-\mathrm{Er}$ fibers are presented. The results for $0.98 \mu \mathrm{m}$ pumping are shown in the lower figure, and the results for $1.48 \mu \mathrm{m}$ pumping are shown in the upper figure of Fig. 3. In the calculations, the optimum cutoff wavelengths are used. As signal wavelengths are used the wavelengths at the emission peak (see Fig. 1). As seen from Fig. 3, the highest gain coefficient is obtained when pumping the $\mathrm{Ge}-\mathrm{Er}$ fiber at $0.98 \mu \mathrm{m}$, where a gain coefficient as high as $23 \mathrm{~dB} / \mathrm{mW}$ is predicted for an NA of 0.4 , this is due to the higher absorption cross section at $0.98 \mu \mathrm{m}$ as well as the higher emission peak at the signal wavelength.

Note that the gain coefficient of $12 \mathrm{~dB} / \mathrm{mW}$ predicted for a $0.98 \mu \mathrm{m}$ pumped $\mathrm{Ge}-\mathrm{Er}$ fiber with an NA of 0.28 (see Fig. 3 ) is in very good agreement with the experimentally obtained gain coefficient of $11 \mathrm{~dB} / \mathrm{mW}$ [2]. 


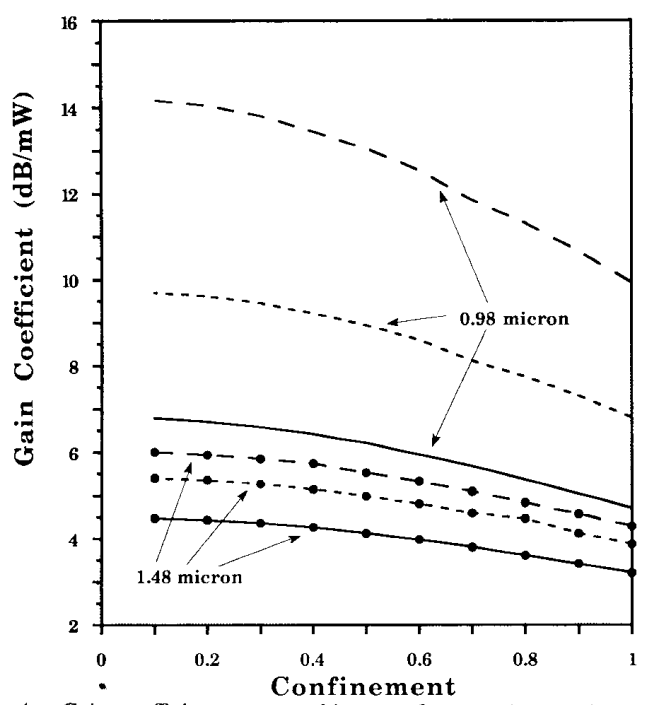

Fig. 4. Gain coefficient versus erbium confinement in step index $\mathrm{Er}^{3+}$ fibers with an NA of 0.25 . Marks: pumping at $1.48 \mu \mathrm{m}$. No marks: pumping at $0.98 \mu \mathrm{m}$. Solid curves: the index raising co-dopant is aluminum. Small dashes: the index raising co-dopants are aluminum and germanium. Long dashes: the index raising co-dopant is germanium.

The maximum obtainable inversion in the upper laser level, $n_{2}^{\max }=\sigma_{12} /\left(\sigma_{12}+\sigma_{21}\right)$, at $1.48 \mu \mathrm{m}$ is almost equal for the three fibers investigated here, $n_{2}^{\max } \approx 0.71$. When pumping at $1.48 \mu \mathrm{m}$ (see Fig. 3), the choice of index raising co-dopant is not significant for the gain coefficient. This is because the absorption cross section at $1.48 \mu \mathrm{m}$ increases when the influence of germanium on the $\mathrm{Er}^{3+}$ ions decreases. With a fixed $n_{2}^{\max }$, this increasing absorption cross section compensates for the decreasing emission peak (see Fig. 1).

The gain coefficient increases with the NA because the overlap integrals between the erbium profile and the two LP modes increase with the NA. However, these overlap integrals can be increased even for a fixed NA by confining the erbium profile. Fig. 4 shows the gain coefficient versus the confinement, i.e., the ratio between the erbium-doping radius and the core radius, for step index fibers with an NA of 0.25 . Fig. 4 shows results for $1.48 \mu \mathrm{m}$ (with marks) and for 0.98 $\mu \mathrm{m}$ pumping of fibers with the three different compositions. As seen from the figure, the improvement in gain coefficient is between 40 and $45 \%$ in all cases, when decreasing the confinement from 1 to 0.1 .

Fig. 5 shows the gain coefficient versus the signal wavelength for the same three types of fiber investigated in Fig. 3. The NA is 0.25 . From Fig. 5 it is seen that the gain coefficient becomes more sensitive to the signal wavelength when the influence of germanium on the $\mathrm{Er}^{3+}$ ions becomes more dominant. Fig. 5 confirms that EDFA should use aluminum as the index raising dopant when broad-band gain characteristics are most desirable.

\section{Conclusion}

A comprehensive model for the erbium-doped fiber amplifier was used to optimize the gain coefficient for step index erbium-doped fibers pumped at 0.98 and $1.48 \mu \mathrm{m}$. The

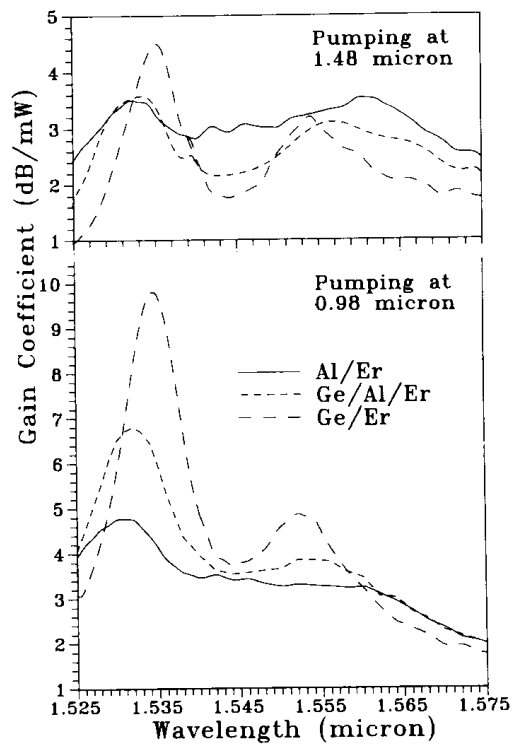

Fig. 5. Gain coefficient versus signal wavelength in step index $\mathrm{Er}^{3}=$ fibers with an NA of 0.25 . Upper figure: pumping at $1.48 \mu \mathrm{m}$. Lower figure: pumping at $0.98 \mu \mathrm{m}$. Solid curves: the index raising co-dopant is aluminum. Small dashes: the index raising co-dopants are aluminum and germanium. Long dashes: the index raising co-dopant is germanium.

optimum cutoff wavelength full core erbium-doped fiber amplifier has been shown to be $0.8 \mu \mathrm{m}$ for $0.98 \mu \mathrm{m}$ pumping, and $0.9 \mu \mathrm{m}$ for $1.48 \mu \mathrm{m}$ pumping. The used of a confined erbium profile was shown to improve the gain coefficient up to $45 \%$. When using germanium as the index raising codopant, the gain coefficient for $0.98 \mu \mathrm{m}$ pumping was found to be twice the value found using aluminum. The gain coefficient was shown to be very sensitive to the signal wavelength when using germanium as co-dopant. Broad-band gain can be obtained if aluminum is the index raising codopant.

\section{ACKNOWLEDGMENT}

The authors wish to thank Dr. E. Nicolaisen for fruitful discussions. Special thanks are given to C. C. Larsen at LYCOM A/S and to K. Dybdal at Jutland Telephone, who provided the fiber parameters.

\section{REFERENCES}

[1] J. L. Zyskind, D. J. DiGiovanni, J. W. Sulhoff, P. C. Becker, and C. H. Brito Cruz, "High performance erbium-doped fiber amplifie pumped at $1.48 \mu \mathrm{m}$ and $0.97 \mu \mathrm{m}$," in Proc. $O A A$ ' 90 , postdeadline paper PDP6.

[2] M. Shimizu, M. Yamada, H. Horiguchi, T. Takeshita, and M Okayasu, "Erbium-doped fiber amplifiers with an extremely high gain coefficient of $11.0 \mathrm{~dB} / \mathrm{mW}$," Electron. Lett., vol. 26, no. 20, pp. $1641-1643,1990$.

[3] B. Pedersen, K. Dybdal, C. D. Hansen, A. Bjarklev, J. H. Povlsen, H. Vandeltorp-Pommer, and C. C. Larsen, "Detailed theoretical and experimental investigation of high-gain erbium doped fiber amplifier," IEEE Photon. Technol Lett, vol. 2, pp. 863-865, 1990.

[4] K. Dybdal, N. Bjerre, J. E. Pedersen, and C. C. Larsen, "Spectroscopic properties of Er-doped silicia fibers and preforms," Proc. SPIE'89, pp. 209-218, 1989.

[5] J. H. Povlsen, A. Bjarklev, B. Pedersen, H. Vendeltorp-Pommer, and K. Rottwitt, "Optimum design of erbium fiber amplifiers pumped with sources emitting at $1480 \mathrm{~nm}, "$ Electron. Lett., vol. 16, no. 17, pp. $1419-1421,1989$ 